\title{
SINUSOIDAL FLICKER CHARACTERISTICS OF THE COLOR-SENSITIVE MECHANISMS OF THE EYE'
}

\author{
DANIEL G. Green \\ Department of Ophthalmology, University of Michigan, Ann Arbor, Michigan, U.S.A.
}

(Received 4 October 1968)

THERE is a body of literature suggesting that temporal factors are of importance in the processing of color information by the visual system. Perhaps most striking, and likewise most difficult to understand in physiological terms, are the illusions of color elicited by flickering achromatic stimuli such as in the well-known Benham's top illusion. More directly, there is evidence that the temporal integrating properties of the three cone systems of trichromatic color vision are different. IKEDA and BOYNTON (1962) have shown that the spectral sensitivity of the eye depends on flash duration, and KeLLY (1962) has similarly demonstrated that frequency of flicker is an important variable in determining the photopic spectral sensitivity of the eye. DE LANGE (1958) reported that when red and green stimuli are sinusoidally alternated in exact antiphase, the eye detects a residual brightness flicker that cannot be eliminated by varying the relative intensities of the stimuli. However, if both the relative proportions of the two lights in the mixture and the phase relations between them are varied, this residual flicker can then be eliminated. It has been suggested by WALRAVEN and LEEBEEK (1964) that these findings reflect frequency-dependent differences in the attenuation and phase characteristics of the color-mediating systems.

Using techniques developed by STILES $(1939,1949)$ wherein a test stimulus, that chiefly stimulates one class of cone, is superimposed on a background which favors the other two, it is possible to arrange matters so that the test stimulus excites only a single cone mechanism. The two-color incremental threshold approach and various modifications, in which the dark light of bleached pigment is substituted for a real light background, have been used to determine the spectral sensitivities (STILES, 1939, 1949; BRINDLEY, 1953; WALD, 1964), dark adaptation properties (Du CROZ and RusHTON, 1965), spatial integrating properties (BRINDLEY, 1954; GREEN, 1968) and after-flash interactions (ALPERN and RUSHTON, 1965) of the separate red, green, and blue mechanisms of color vision. Recently, using on-off blue flicker superimposed on a yellow background, BRINDLEY, DU CROZ and Rushton (1965) have shown that the blue cone mechanisms have a greatly depressed critical flicker fusion frequency. The experiments presented here were designed to extend these observations by measuring the flicker thresholds for sinusoidally modulated red, green, and blue stimuli superimposed on bright backgrounds of a complementary color. The object of these experiments was the determination of the temporal frequency response curves, the so-called de Lange characteristics, of the separate cone mechanisms.

1 This work was assisted by National Institutes of Health USPHS Grant NB 07579. 
The intensity variations as a function of time for a sinusoidally modulated light of average intensity $I_{0}$ can be expressed as:

$$
I(t)=I_{0}(1+m \sin 2-f t)
$$

where $m$ is the depth of modulation and $f$ is the flicker frequency. In general, when a sinusoidally flickering light of modulation $m$ is superimposed on a background of the same or of a different color, the effective modulation of the composite target is less than $m$.

Consider, for example, a photoreceptor with a spectral absorption curve $\rho(\lambda)$. If this photoreceptor is illuminated with a combination of a sinusoidally flickering light of wavelength $\lambda_{1}$ and irradiance $E_{1}$ and a background of wavelength $\lambda_{2}$ and irradiance $E_{2}$, the temporal variation in the number of quanta absorbed by the photoreceptor is given by the relationship:

$$
U(t)=E_{1} \rho\left(\lambda_{1}\right)(1+m \sin 2-f t)+E_{2} \rho\left(\lambda_{2}\right)
$$

or

$$
=\left(E_{1} \rho\left(\lambda_{1}\right)+E_{2} \rho\left(\lambda_{2}\right)\right)\left(1+\frac{m E_{1} \rho\left(\lambda_{1}\right)}{E_{1} \rho\left(\lambda_{1}\right)+E_{2} \rho\left(\lambda_{2}\right)} \cdot \sin 2-f f\right) .
$$

It follows that when a flickering light of one color is superimposed on a background of another color the temporal variations in absorbed flux will be differently modulated in receptors with different absorption spectra. In the case of human color vision, which we have good reason for believing is mediated by three kinds of cone with each cone containing the same visual pigment (MARKs, DOBELLE and MACNicHOL, 1964), the above observation provides the basis for designing an experiment in which a flickering stimulus is detected by only a single kind of cone.

In contrast to the experiments to be reported here, where a small, centrally fixated test stimulus is added to a much larger adapting field, KELLY (1962) has measured the sinusoidal frequency response of the visual system using a large "edgeless" field with the color of the flickering component different from that of the steady component. In the light of the nonuniformities in the distribution of receptor types over the retina, it is perhaps not surprising that his results show great complexity. It has not been possible to relate his findings to the present results obtained using conditions known to isolate the properties of the color-receptive systems in a local area of the retina.

\section{METHOD}

The optical system is shown in Fig. 1. It consisted of two channels seen in Maxwellian view. One of these channels produced the background field and the other the test field. To form the background, the image of the filament of a tungsten source (S) was formed by $L_{1}$ on an artificial pupil (AP). The background field was $12^{\circ}$ in dia. The second channel produced a flickering test field, $2 \cdot 0^{\circ}$ dia., centered in the back-

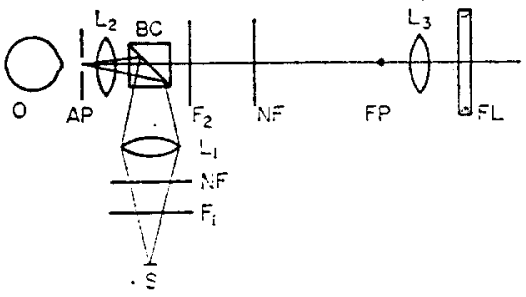

Fig. 1. Diagrammatic representation of the apparatus. 
ground. This field was formed by imaging the light from a Mazda Daylight fluorescent tube (FL) on the artificial pupil. The color and intensity of the background and test fields were varied by means of neutral density filters (NF) and Kodak Wratten filters $\left(F_{1}, F_{2}\right)$ placed in the two channels. The background was colored: (a) purple, using a Wratten no. 35 which transmits wavelengths shorter than $462 \mathrm{~nm}$ and longer than $645 \mathrm{~nm}$; (b) blue-green, using a Wratten no. 44A, a filter with a dominant wavelength of $492 \mathrm{~nm}$ and maximum transmission at $480 \mathrm{~nm}$; (c) yellow, using a Wratten no. 21 , which transmits wavelengths longer than $540 \mathrm{~nm}$ and has a dominant wavelength of $594 \mathrm{~nm}$; (d) white, using Wratten color-correcting filters nos. $78 \mathrm{~B}$ and $80 \mathrm{~B}$. The following filters were used in the test field: Wratten no. 47 (blue) which has a dominant wavelength of $470 \mathrm{~nm}$ and maximum transmission at $430 \mathrm{~nm}$; Wratten no. 74 (green) which has a dominant wavelength of $539 \mathrm{~nm}$ and transmits maximally at $530 \mathrm{~nm}$; Wratten no. 92 (red) which has a dominant wavelength of $648 \mathrm{~nm}$ and transmits wavelengths longer than $630 \mathrm{~nm}$. With each of the above filters the test field produced a retinal illumination of about 540 effective trolands.

The intensity of the test field was sinusoidally flickered by applying voltages of varying amplitude and frequency to a feedback circuit which controlled the current through the fluorescent tube. As reported by SPERLINo (1965), the light output was found to be a linear function of the tube current over a range exceeding 10 to 1 with no appreciable color change. Measuring the output of the tube with an RCA type 934 vacuum photocell, it was found that the frequency response of the light control system was flat, $\pm 1 \mathrm{db}$, from 0 to $500 \mathrm{cps}$.

The subjects, whose pupils had been dilated with 0.5 per cent tropicamide (Mydriacyl), were fixed in the apparatus by means of a bite bar and viewed the target through a $4 \mathrm{~mm}$ artificial pupil (AP). A spectacle lens $\left(L_{2}\right)$ was used to bring the flickering field, which was $114 \mathrm{~cm}$ from the artificial pupil, into focus on the retina. The subjects, who had normal color vision, adjusted a ten-turn potentiometer controlling the modulation of the sinusoidal flicker until they were satisfied that the flicker could just be detected. To average out any possible effects of prior adaptation to flickering lights (ALPERN and SUGIYAMA, 1961) measurements were made, two settings at each frequency, starting at the lowest frequency and systematically increasing the frequency of flicker and then systematically decreasing ficker frequency. All the data points are the averages of measurements made in two such experimental runs and are therefore the averages of eight settings.

\section{RESULTS}

\section{Green ficker on a purple background}

In particular, to isolate the green mechanism a flickering green stimulus of limited extent was superimposed on a much larger bright purple background. The amount by which it is possible to reduce the temporal modulation for the red and blue receptors relative to the green receptors is determined by the pigments they contained. If one uses estimates of the spectral sensitivities of the red, green, and blue foveal pigments such as those of WALD (1964), it is clear that since the absorption spectra are broad and overlapping it is not possible to depress the modulation in both the red and blue cones without also reducing the modulation for the green cones. Nevertheless, one estimates that the effect can be made about a factor of 10 greater upon the red and blue than upon the green receptors.

Figure 2 shows the results of measuring the modulation thresholds for sinusoidal green flicker on a purple background on two subjects. The amount by which the purple background depresses the sensitivity of the green system depends on the relative intensities of test and background. The measurements indicated with filled symbols were determined with the luminance of the purple background adjusted so that at peak modulation sensitivity the threshold modulation was about 10 per cent. This background produced a retinal illumination of $3.7 \mathrm{log}$ trolands. Under these conditions one might expect that even 100 per cent modulated flicker would be below threshold for the red and blue systems. To estimate the extent by which the modulation sensitivity of the green mechanism is depressed by the purple background, measurements have been made at each temporal frequency with (filled symbols) and without (open symbols) a neutral density filter before the flickering field. The details of the estimating procedure will be given later; for the moment it suffices to note that the modulation thresholds are changed by unbalancing the relative intensities of the test and background fields. 


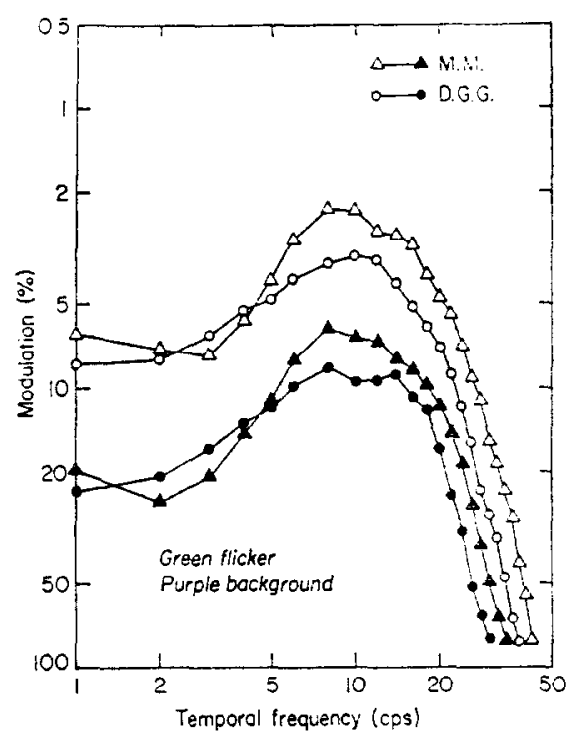

Fig. 2. Modulation thresholds for green flicker on a purple background. Measurements give the modulation of the test field at which flicker could just be detected when the test field is superimposed on a bright background of a complementary color. Results from two subjects, D.G.G. (circles) and M.M. (triangles) are shown. The points indicated with filled symbols were obtained with a test illuminance of $2.1 \mathrm{log}$ effective trolands and the background illuminance adjusted to depress the peak of the de Lange characteristic to about 10 per cent modulation threshold. Open symbols show measurements obtained with the mean illuminance of the test field increased by a factor of $4 \cdot 5$.

The results of this experiment show that with green flicker/purple background the sinusoidal flicker characteristic is very much like that described for white flicker by DE LANGE (1958). That is, near one cps the characteristics are almost horizontal. Up to about $10 \mathrm{cps}$, the modulation required by the subject to see flicker decreases. For frequencies higher than this optimum frequency, the modulation sensitivity-the reciprocal of threshold modulation-rapidly decreases.

\section{Red flicker on a blue-green background}

In the next experiment, a red flickering stimulus and a blue-green background were used to isolate the red mechanism. The results of this experiment are shown in Fig. 3. As in Fig. 2, the background was adjusted in intensity so that the peak modulation sensitivity was about a factor of ten above 100 per cent modulated threshold (filled symbols). This blue-green background produced a retinal illumination of $3.2 \mathrm{log}$ trolands. The open symbols are measurements obtained after the test was brightened by removing a neutral density filter. Unlike the results shown in Fig. 2, the frequency characteristics are different from that ordinarily obtained using achromatic flicker. For both subjects the characteristics are nearly horizontal from one cps up to about $8 \mathrm{cps}$. Above this frequency there is the usual rapid attenuation with increasing frequency.

\section{Blue ficker on a yellow background}

Figure 4 shows the results of measuring the modulation thresholds for a blue flickering test field superimposed on a bright yellow background. The yellow background produced a retinal illumination of $5 \cdot 2 \mathrm{log}$ trolands. This intensity is known, from earlier work on 


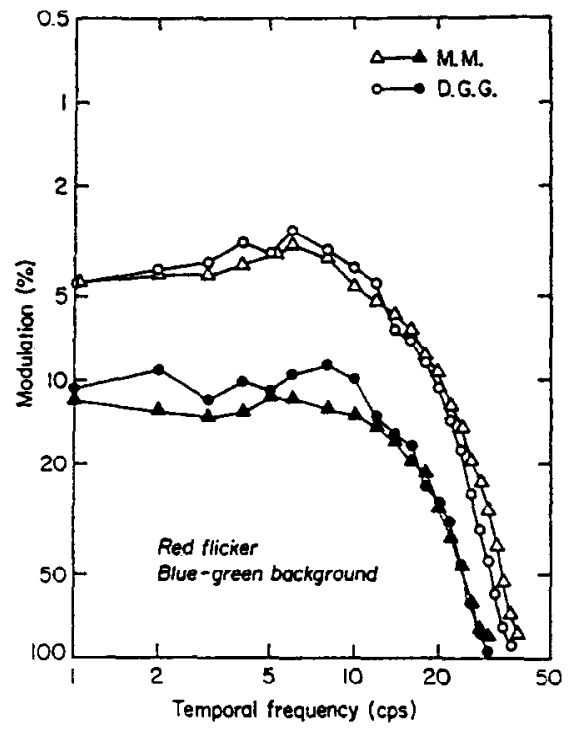

FIG. 3. Modulation thresholds for red flicker on a blue-green background. Other details as for Fig. 2.

the visual acuity of the blue mechanisms (GREEN, 1968), to isolate the blue system. The solid and open symbols are related to each other as in the previous figures. However, in

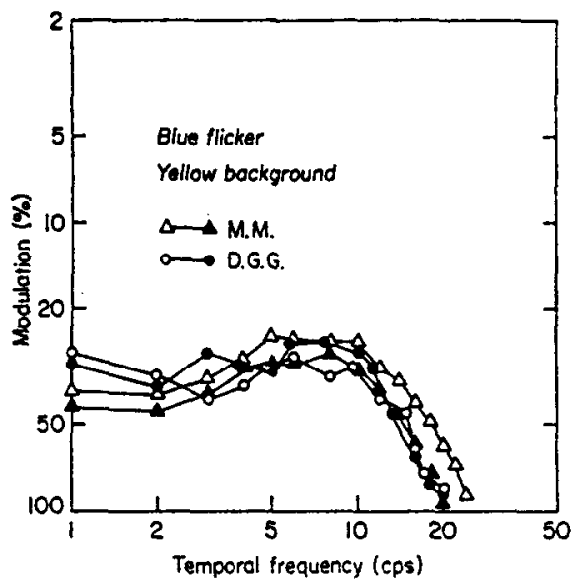

Fig. 4. Modulation thresholds for blue flicker on a yellow background. The yellow background produced a retinal illuminance of $5.2 \mathrm{log}$ trolands. At this illuminance the blue cone mechanisms are known to be isolated. All other details as for Fig. 2.

contrast with the previous findings, brightening the test field has little or no effect on the measured modulation thresholds. This indicates that the yellow background is not depressing the sensitivity of the receptive system determining the modulation thresholds, thus confirming that the yellow background has isolated the blue mechanisms. Quite clearly, the blue system has a much lower modulation sensitivity than either the green or red systems. The available measurements of the high frequency fall-off in modulation 
sensitivity define a curve similar in shape to that found with red flicker/blue-green background or with green flicker/purple background.

\section{Modulation sensitivity}

The preceding results do not allow direct comparison of the response curves determined with different pairs of colors. Before this can be done there is the practical difficulty that the positions of the curves shown in Figs. 2 and 3 are necessarily arbitrary. The background illuminances were selected so as to place the lowermost sets of measurements (solid symbols) in a particular position along the modulation axis. A consistent method of assessing the relative sensitivities of the red, green, and blue mechanisms is needed. The problem is one of determining the modulation when the experimental conditions have been selected so that the flickering test target is detected by a single color mechanism. From equation (2) the modulation in a receptor having an absorption spectra $\rho(\lambda)$ is given by:

$$
m^{*}=m E_{1} \rho\left(\lambda_{1}\right) /\left[E_{1} \rho\left(\lambda_{1}\right)+E_{2} \rho\left(\lambda_{2}\right)\right] .
$$

or

$$
m^{*}=m /\left(1+\frac{E_{2} \rho\left(\lambda_{2}\right)}{E_{1} \rho\left(\lambda_{1}\right)}\right) .
$$

Clearly, if one uses monochromatic sources of known energy and if the absorption spectrum of the pigment in question is known, then the modulation of the stimulus at threshold can be determined by direct calculation. The above approach is not practicable since none of the relevant quantities are known with sufficient precision. Fortunately it is possible to take a purely experimental approach to determining the effective modulation (GREEN, 1968).

The extent by which the background depressed the modulation of the test field was determined by increasing the energy in the test field by a known amount and measuring the resulting change in modulation sensitivity. In the cases in question, the energy in the test field was increased by a factor of 4.5 by removing a neutral density filter from in front of the test field. Brightening the test field decreases the threshold modulation from $m_{1}$ to $m_{2}$. Because the background field is much brighter than the test field, the net change in luminance is small, and it seems reasonable to assume that the threshold for the composite target remains the same. It then follows from the above assumption that:

$$
m^{*}=m_{1} /(1+\eta)=m_{2} /(1+\eta / 4 \cdot 5)
$$

where $\eta=E_{2} \rho\left(\lambda_{2}\right) / E_{1} \rho\left(\lambda_{1}\right)$. Solving the above equation for $\eta$, the following relationship is obtained:

$$
\eta=\left(m_{1} / m_{2}-1\right) /\left(1-m_{1} / 4 \cdot 5 m_{2}\right) .
$$

Once $\eta$ has been calculated, it is possible using equation (5) to express the measurements in terms of the effective modulation. First, however, it seemed reasonable to assess the correctness of equation (6) by using it to calculate the modulation when the test and background were the same color.

The measurements shown in Fig. 5 were obtained by superimposing a white test of the same photopic brightness as the colored test fields upon a white background. As in previous experiments, one set of measurements (filled circles) was obtained after the intensity of the background had been adjusted so that the threshold was about 10 per cent at peak 


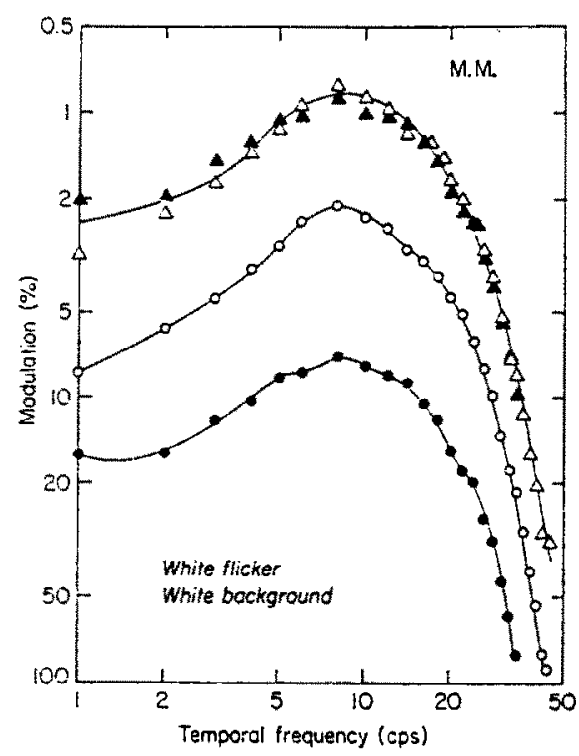

Fig. 5. Modulation thresholds for white flicker on a white background. Measurements shown as filled circles give the modulation of the test feld at which ficker could just be detected when the test field is superimposed on a bright white background. Open circles show similar measurements obtained after the mean luminance of the test field was increased by a factor of 4.5. The triangles give the effective modulation thresholds for the complete target. The triangles are both sets of measurements shown as circles shifted along the log modulation axis. See the text for the details of the procedure used to determine the amount by which each set of points is shifted.

modulation sensitivity. This white background produced a retinal illuminance of $3.0 \mathrm{log}$ trolands. Removing a neutral density filter, the intensity of the test was increased by a factor of 4.5. A second set of measurements (open circles) was then obtained. From the two sets of measurements $m_{1} / m_{2}$, the ratio of thresholds with and without the filter before the test was calculated at each temporal frequency. The mean ratio obtained was $3.15 \pm 0.09$ (S.E. of the mean). Using this figure in equation (6), $\eta$ was calculated to be $7 \cdot 17 \pm 0.83$ (S.E. of the mean). A bipartite field was formed by carefully blocking off opposite halves of the test and background fields. The background and test fields could then be matched in both color and brightness by varying the position of a neutral density wedge placed before the background field. By direct visual comparison it was determined that the background had to be attenuated by a factor of 8.0 to match the test. This is in reasonable agreement with the value of $\eta$ found by the estimating procedure. Using the calculated value of $\eta$ in equation (5), the two sets of measurements have been shifted along the log modulation axis into their correct position (triangles) when expressed in terms of the modulation of the complete target composed of both test and background fields. A smooth curve has been drawn through the two sets of shifted measurements.

Table 1 summarizes the results of applying the estimating procedure to the experiments using colored flicker on complementary backgrounds. The calculated means with their standard errors are tabulated for both the quantities $m_{1} / m_{2}$ (the ratio of the thresholds with and without an attenuating filter) and $\eta$ (the ratio of effective background and test intensities). By using the calculated values of $\eta$ in equation (5), the measurements shown in Figs. 2, 3 and 4 have been replotted (Fig. 6) on an effective modulation scale. 
TABLE 1.

\begin{tabular}{|c|c|c|c|c|}
\hline & & Red & Green & Blue \\
\hline $\begin{array}{c}\text { Subject M.M. } \\
m_{1} / m_{2} \\
r_{1}\end{array}$ & $\begin{array}{l}3.09 \\
6.66\end{array}$ & $\begin{array}{l} \pm 0.06 \\
\pm 0.61\end{array}$ & $\begin{array}{l}2.87 \pm 0.08 \\
5.17 \pm 0.50\end{array}$ & $\begin{array}{l}1.24=0.04 \\
0.31=0.08\end{array}$ \\
\hline $\begin{array}{c}\text { Subject D.G.G. } \\
\quad m_{1} / m_{2} \\
\eta\end{array}$ & $\begin{array}{l}2.68 \\
4 \cdot 16\end{array}$ & $\begin{array}{l} \pm 0.08 \\
\pm 0.40\end{array}$ & $\begin{array}{l}2.57 \pm 0.08 \\
3.65 \pm 0.35\end{array}$ & $\begin{array}{r}0.95 \pm 0.04 \\
-0.05 \pm 0.05\end{array}$ \\
\hline
\end{tabular}

\section{DISCUSSION}

The blue cone mechanisms have been shown to differ from the other color-receptive systems in a number of properties. The blue mechanisms have a lower visual acuity (STILES, 1949; BRINDLEY, 1954), higher Weber fractions (STILES, 1939), greater spatial summation (BRINDLEY, 1954), and lower contrast sensitivity for sine-wave gratings (GREEN, 1968). Recently, BRINDLEY et al. (1965) have reported that the blue mechanisms have a lower critical flicker fusion frequency.

The frequency at which 100 per cent modulated flicker is fused is a single point at the high frequency extreme of the de Lange characteristic. The results shown in Fig. 6 make it apparent that the major cause for the depressed flicker fusion frequency of the blue mechanism is its depressed modulation sensitivity. There are clear differences in the low
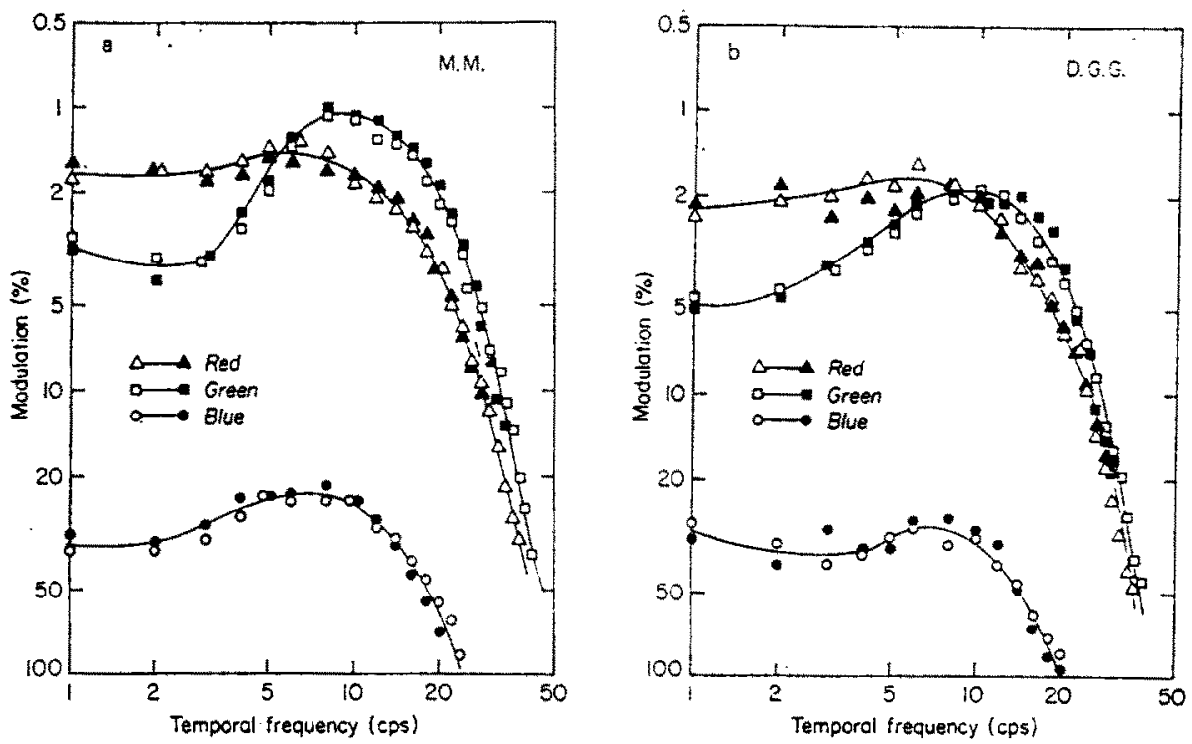

FiG. 6. (a) De Lange characteristics of the red, green and blue mechanisms (subject D.G.G.). Squares are the two sets of measurements determined with green flicker on a purple background repositioned using the procedure described in the text to give the effective modulation thresholds for the complete target made up of background and test fields. The points indicated by triangles are the measurements obtained with red ficker on a blue-green background replotted in terms of the effective modulation. Likewise, the circles are the measurements for blue flicker on a yellow background replotted. (b) Similar resuits from a second subject (M.M.). 
frequency region between the de Lange characteristic for the blue and those for the green. However, the high frequency portion of the blue de Lange characteristic is very similar in shape to those of the red and green mechanisms. Due to the depressed sensitivity of the blue mechanisms, only a limited part of the high frequency fall-off is available for comparison. The available measurements show no signs of the blue curve being shifted towards the low frequencies as would be expected if the processes mediating blue vision were for some reason relatively slow. This suggests that the depressed flicker fusion frequency of the blue mechanisms may not be an independent property and may only reflect the well-known fact that the mechanisms have an elevated Weber fraction.

Previous work on the properties of the red and green mechanisms have uncovered very few differences other than spectral sensitivity. However, as a result of these experiments it seems clear that the low frequency portions of the de Lange characteristics of the red and green mechanisms are quite different. Since we have no real insight into the causes for the low frequency fall in sensitivity, it is difficult to appreciate the significance of the red-green differences. The automatic gain-control model proposed by FUORTES and HODGKIN (1964) provides an attractive way of thinking about the peaked frequency responses of the visual system. The Fuortes-Hodgkin model is a filter with 10 identical stages, each of which is described by a first-order differential equation. The output of the filter is fed back to each stage and changes the parameters in the differential equation. As PINTER (1966) has shown, this model can exhibit peaked frequency response characteristics similar to the kind shown in Figs. 2 and 5. A resonance in the flicker response characteristic occurs because, as the frequency increases, the negative feedback of the automatic gain-control turns into positive feedback due to the phase-shifts around the feedback loops. If the peaked frequency response characteristics determined psychophysically are caused by an automatic gain-control (A.G.C.), then it is necessary to postulate differences in the A.G.C. organization for the red and green mechanisms. Du CROZ and Rushton (1966) have shown that there are separate and independent A.G.C. systems for each of the color mechanisms. With this kind of arrangement it seems possible for each A.G.C. to have its own frequency response characteristic.

For the automatic gain-control system of Fuortes and Hodgkin, a threshold measurement is equivalent to measuring the small-signal temporal transfer function. Under small-signal conditions the Fuortes-Hodgkin model becomes a linear filter with negative, linear feedback from the output. In linear filters there are general relationships between the logarithmic-amplitude characteristics and the minimum-phase characteristics (BODE, 1945). On the basis of this kind of consideration, one expects that the differences in the shapes of the attenuation characteristics for the red and green mechanisms would lead to differences in their phase characteristics. At low frequencies the output of the red system should lag behind the green. Conversely, for frequencies above the response peak the output of the red system should lead the green. WALRAVEN and LeEBEEK (1964) have measured the phase shift between sinusoidally modulated alternating colored stimuli. Their results show the expected phase relations between red and green stimuli, including the reversal in phase at approximately the resonance peak in the amplitude characteristics.

\section{REFERENCES}

AlPERn, M. and Rushton, W. A. H. (1965). The specificity of the cone interaction in the after-fiash effect. J. Physiol. 176, 473-482.

AlPern, M. and Sugryama, S. (1961). Photic driving of the critical flicker frequency. J. opt. Soc. Am. 51, 1379-1385. 
BODE, H. (1945). Network Analysis and Feedback Amplifier Design, Van Nostrand, New York, N.Y.

BRINDLEY, G. S. (1953). The effects on colour vision of adaptation to very bright lights. J. Physiol. 122, $332-350$.

BRNDLEY, G. S. (1954). The summation areas of human colour-receptive mechanisms at increment threshold. J. Physiol. 124, 400-408.

Brundiey, G. S., Du CROZ, J. J. and Rushton, W. A. H. (1966). The flicker fusion frequency of the bluesensitive mechanism of colour vision. J. Physiol. 183, 497-500.

DE LANGE, H. (1958). Research into the dynamic nature of the human fovea-cortex systems with intermittent and modulated light. J. opt. Soc. Am. 48, 777-789.

Du CROz, J. J. and Rushton, W. A. H. (1966). The separation of cone mechanisms in dark adaptation. J. Physiol. 183, 481-496.

Fuortes, M. G. F. and Hodgkin, A. L. (1964). Changes in time scale and sensitivity in the ommatidia of Limulus. J. Physiol. 172, 239-263.

GrEeN, D. G. (1968). The contrast sensitivity of the colour mechanisms of the human eye. J. Physiol. $196,415-429$.

IKEDA, M. and BOYNTON, R. M. (1962). Effect of test-flash duration upon the spectral sensitivity of the eye. J. opt. Soc. Am. 52, 697-699.

Kelly, D. H. (1962). Visual responses to time-dependent stimuli. IV. Effects of chromatic adaptation. J. opt. Soc. Am. 52, 940-947.

Marks, W. B., Dobelle, W. H. and MacNichol, E. F. (1964). Visual pigments of single primate cones. Science, N.Y. 143, 1181-1183.

Pinter, R. B. (1966). Sinusoidal and delta function responses of visual cells of the Limulus eye. J. gen. Physiol. 49, 565-593.

SperLING, G. (1965). Temporal and spatial visual masking. I. Masking by impulse flashes. J. opt. Soc. Am. 55, 541-559.

StILES, W. S. (1939). The directional sensitivity of the retina and the spectral sensitivities of the rods and cones. Proc. R. Soc. Lond. B127, 64-105.

StrLES, W. S. (1949). Incremental thresholds and the mechanisms of colour vision. Documenta Ophthal. 3, $138-163$.

StILES, W. S. (1959). Color vision: The approach through incremental threshold sensitivity. Proc. Natl Acad. Sci. 45, 100-114.

WALD, G. (1964). The receptors of human color vision. Science, N.Y. 145, 1007-1017.

Walraven, P. L. and Leebeek, H. J. (1964). Phase shift of sinusoidally alternating colored stimuli. J. opt. Soc. Am. 54, 78-82.

Abstract-The flicker characteristics of the color-receptive systems of the eye were investigated by measuring the modulation thresholds for sinusoidal flicker of one color superimposed on a background of a complimentary color. A procedure is outlined that allows the ficker characteristics determined using red, green and blue stimuli to be compared. The results obtained indicate that the red and green mechanisms have frequency response characteristics with about equal peak sensitivity but differing in shape at low and intermediate rates of flicker. The blue-sensitive mechanism has a reduced ficker fusion frequency which seems to be due largely to the depressed modulation sensitivity of the mechanism.

Résumé-On étudie les caractéristiques en papillotement des systèmes de réception de la couleur dans l'oeil en mesurant les seuils de modulation d'un papillotement sinusoidal d'une couleur superposé a un fond ce couleur complëmentaire. On expose une méthode qui permet la comparaison des caractéristiques du papillotement avec des stimuli rouge, vert et bleu. Les résultats indiquent que les mécanismes rouge et vert ont des caractéristiques de réponse à la fréquence qui ont à peu près la même sensibilité maximum mais une forme différente aux fréquences de papillotement basses ou moyennes. Le mécanisme sensible au bleu possède une fréquence critique de fusion réduite, qui semble due surtout à la sensibilité à la modulation plus faible pour ce mécanisme.

Zusammenfassung-Es wurden die Flimmerkennzeichen des Farbempfangsystems des Auges durch eine Messung der Modulationsschwelle für Sinusflimmerreize einer Farbe auf dem Hintergrund ihrer Komplementärfarbe untersucht. Es wird ein Versuchsverahren beschrieben, welches es erlaubt die mit roten, grünen und blauen Reizen ermittelten Flimmerkennzeichen zu vergleichen. Die Ergebnisse zeigen an, dass das rote und grüne System mit einer ungefähr gleichen Gipfelfrequenzempfindlichkeit antwortet, aber dass es bei niedrigen und mittleren Flimmerfrequenzen Formunterschiede gibt. Das blau-empfindliche System ist durch eine verringerte Fusionsfrequenz, die grösstenteils von einer verminderten Modulationsempfindlichkeit verursacht wird, gekennzeichnet. 
Резюме - Особенности реакций цветовоспринимағщей системы глаза в ответ на мелькаюший свет были исследованы путем измерения порогов модуляшин мельканй одного цвета, изменяющихся синусоидально и налагаемых на фон дополнительного ивета. Опыты были поставлены так, что позволяли сравнивать характеристики реакии на мелькания при использовании красного, зеленого и синего иветовых стимулов. Полученные результаты показывают, что красный и зеленый механизмы имеют характеристики реакций на частоту с приблизительно равным максимумом чувствительности, но отличающиеся по форме при низких и средних частотах. Механизм чувствительный к синему имеет пониженную критическую частоту слияния мельканий, которая, повидимому, обусловливается, в значительной степени, понюкенной чувствительностью его к восприятию модуляций. 